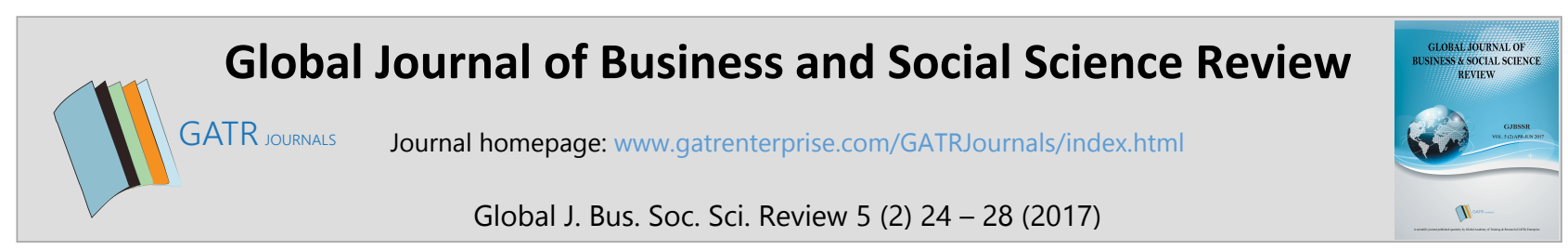

\title{
The Association between Big-Five Personality and Property Deviance
}

\author{
Aida Abdullah ${ }^{1 *}$ and Sabitha Marican ${ }^{2}$ \\ ${ }^{1}$ Senior Lecturer, Faculty of Administrative Science and Policy Studies, Universiti Teknologi Mara, Kampus Seremban 3, 70300 \\ Seremban, Negeri Sembilan, Malaysia \\ ${ }^{2}$ Associate Professor, Faculty of Economics and Administration, University of Malaya, 50603 Kuala Lumpur, Malaysia
}

\begin{abstract}
Objective - Property deviance is an inverse behaviour that has received widespread attention from all forms of organisations. This behaviour can be characterised as theft, embezzlement, bribery and corruption. The public sector has experiences wide exposure to this behaviour due to its prevalence among public sector employees. Thus, in this study, emphasis is given to the personality of the public administrator in identifying the contribution of personality in curbing property deviance.

Methodology/Technique - The study was conducted on public organisations and questionnaires were distributed to public administrators using a convenience survey. The questionnaire uses the Big-Five Personality Dimensions developed by Lussier (2008), whilst the property deviance uses a three-item questionnaire developed by Robinson and Bennett (1995). Data was analysed through correlation analysis.

Findings - The findings demonstrated that personality does contribute to property deviance, with all dimensions of personality having a significant negative association with property deviance. These findings highlight major implications for public organisations in identifying the personality of their staff, in order to control the rate of property deviance and establishing a system for translating these findings into action to be taken, in order for the existing staff and future employees to regulate desirable workplace behaviour.

Novelty - The study suggests that screening should be conducted periodically in the selection process as well as in the form of employee training for staff with the personality traits found in people likely to engage in property deviance.

Type of Paper: Empirical.
\end{abstract}

Keywords: Property Deviance; Personality; Surgency; Conscientiousness; Agreeableness; Emotional Stability; Openness to Experience.

JEL Classification: J24, J28.

\section{Introduction}

Organisations face various behavioural problems, including issues pertaining to work attendance, unproductive, inefficiency, and employee incompetence. They also face issues relating to irregularities of money, time, trust and the property of the organisation. The latter is specifically concerned with property deviance, which can be detrimental to the organisation both economically and socially (Kantur, 2010). Property deviance deeply affects an organisation, especially public organisations, which may affect their reputation and

\footnotetext{
* Paper Info: Revised: December 16, 2016

Accepted: April 26, 2017

* Corresponding author:

E-mail: aida547@ns.uitm.edu.my

Affiliation: Faculty of Administrative Science and Policy Studies, Universiti Teknologi Mara, Malaysia.
} 
accountability in the public eye. Past studies have examined deviant behaviour with a general approach, without specific emphasis on property deviance issues or personality traits of perpetrators and victims of property deviance; something that is common in public organisations (Mehmood \& Arif, 2011).

Previous studies on the issue of deviance recognise that personal resources are instrumental. Most researchers have investigated the role of personal resources such as esteem levels, efficacy levels, type of personality and personality traits contributing to deviant behaviour. Studies have found that personality is the dominant factor that shapes the character, attitude, and perceptions of a person as expressed through their behaviours. This study will assess the contribution of personality to property deviance based on five main personality types (Hudson, Roberts, \& Lodi-Smith, 2012; Vakola, Tsaousis, \& Nikolaou, 2004).

\section{Literature Review}

Property deviance can be defined as the misuse of financial resources and property of the organisation. Behavioural traits that characterise property deviance include stealing, corruption, bribe and utilisation of resources without the permission of the organisation. This conduct is considered contrary to the norms and culture of the organisation, and has both direct and indirect implications for the individual and the organisation as a whole (Agboola \& Salawu, 2011; Kantur, 2010).

Studies show that deviance could hinder the achievement of the organisation's objectives due to the failure of employees to maintain the organisation's ethical values, tarnished organisational image and increased public dissatisfaction. This negative behaviour also affects social relationships, causing others to feel uncomfortable, emotionally unstable and may expose an individual to various types of health problems. As a result, the organisation may lose competent workers who demonstrates dissatisfaction, revolt or leave the organisation due to such deviant conduct (Farhadi, Fatimah, Nasir, \& Wan Shahrazad, 2012; Ghosh, Dierkes, \& Falletta, 2011).

In the public sector, some public employees become perpetrators, intermediaries or observers which allows such deviant acts to occur. Whilst studies have found that the frequency of property deviance is still low, it has huge financial implications when it does occur and this behaviour may lead the organisation to adopt negative cultures and values. As such, this act should be contained and avoided (Giauque, Anderfuhren-Biget, \& Varone, 2012).

Past studies have indicated that personality type is highly associated with property deviance. Personality is defined as a psycho-social dimension which explains an individual's character. Personality is formed either through heredity or environment, or a combination of both and determines a person's attitude towards the environment including; behaviours toward an object or individual and to what extent we agree, disagree, approve or disapprove. By referring to previous studies, personality is referred to as types and traits, with traits being the most widely used tool in identifying performance, behaviour, and attitude (Lodi-Smith \& Roberts, 2007).

This study focusses on the big-five personality traits which explain the five taxonomies of human personality at work including; surgency, agreeableness, adjustment, conscientiousness and openness to experience. The big-five personality model describes the attitudes of an individual and their reactions towards the environment. A person who possesses high levels in all personality dimensions has the ability to better handle work matters through their evaluative judgement; their selection action is often positive. In contrast, people with low personality dimensions show undesirable behaviours. They lack courage in doing jobs, face high levels of conflict, are unable to meet the demands of work, experience dissatisfaction, and are dependent on various incentives to maintain their motivation, all of which increase deviance tendencies (Betz \& Borgen, 2010). 


\section{Research Methodology}

The study is descriptive and adopts a cross-sectional survey by focusing on managerial employees in Malaysian federal ministries. According to Andrews and Boyne (2010), managerial employees are a critical workgroup and are involved in aligning organisational counterparts. In deviance studies, it is useful to determine the manager's perception in relation to deviance, as previous studies have lacked a focus on the contribution of managerial employees towards this issue. The samples are selected using a non-probability convenience sampling method to maximise participant willingness in responding to the sensitive deviance issues, and to protect their confidentiality (Biron, 2010). As such, the results cannot be generalised, and the data might not reflect the overall situation in the Malaysian federal ministries. However, the results are beneficial in indicating an association between personality traits and property deviance that calls for proactive actions. The 25 itemed questionnaire used to measure personality was developed by Lussier (2008), and each personality dimension is assessed by five items. For property deviance, a three items questionnaire developed by Robinson \& Bennet (1995) was used. The respondents were asked to report how frequently they observed personality dimensions and property deviance, scored using the Likert scale range from (1) Never, (2) Rarely, (3) Often and (4) Very Often. The hypothesised relationships were analysed using correlation analysis. Descriptive analysis and correlation analysis were also applied.

\section{Results and Discussion}

\subsection{Respondents' Profile and Descriptive Analysis}

A total of 181 respondents participated in this study. The majority of the respondents were between $31-40$ years of age $(50.8 \%)$. In terms of gender, $39.8 \%$ constituted male respondents and $59.7 \%$ female respondents. The majority of the respondents were married (65.2\%), and 34.7\% were unmarried. The data also showed that the majority of the respondents were Muslims (90.6\%) having a bachelor's degree (51.4\%).

Table 1 represents the mean and standard deviations of the studied variables. For the dependent variables, it was reported that the mean value for property deviance is 3.812, indicating that the act of property deviance is frequently observed in the surveyed organisations. As mentioned by Robinson and Bennett (1995), property deviance is categorised as a major offence and can be reported to the organisation. The subsequent disciplinary action in the form of warnings, suspension or termination may apply to those involved.

The table shows that all instruments have good internal consistency with the Cronbach Alpha reported between .770 and .900 . For the personality dimensions, the findings revealed that the highest was conscientiousness (3.35), followed by adjustment (3.22) and agreeableness (3.19). The lowest reported was surgency (2.89) and openness to experience (2.93). Overall, the personality dimensions were high, as most of the respondents scored between 3 (often) and 4 (very often). Conscientiousness is the most frequently observed personality, and surgency is the least observed. The results also indicate that all personality dimensions have an association with organisational and interpersonal deviance, based on the Pearson Product Moment coefficient value. All personality dimensions show a significant negative relationship with significant medium and small correlation with property deviance.

Table 1. Descriptive Statistic, Scale Reliability and Correlation Matrix

\begin{tabular}{|l|l|l|l|l|l|l|l|l|l|l|}
\hline No. & Variable & Mean & SD & R & $\mathbf{1}$ & $\mathbf{2}$ & $\mathbf{3}$ & $\mathbf{4}$ & $\mathbf{5}$ & $\mathbf{6}$ \\
\hline 1. & Property Deviance & 3.812 & 1.219 & .770 & 1 & & & & & \\
\hline 2. & Surgency & 2.886 & .472 & .775 & -.128 & 1 & & & & \\
\hline 3. & Agreeableness & 3.188 & .431 & .900 & -.279 & .734 & 1 & & & \\
\hline 4. & Adjustment & 3.218 & .441 & .882 & -.287 & .696 & .858 & 1 & & \\
\hline 5. & Conscientiousness & 3.346 & .444 & .814 & -.315 & .631 & .823 & .859 & 1 & \\
\hline 6. & Openness to experience & 2.934 & .517 & .837 & -.217 & .781 & .811 & .768 & .678 & 1 \\
\hline
\end{tabular}

$* * \mathrm{p}<.0 .01, * \mathrm{p}<0.05$ 


\subsection{The Association Between Big-five Personality and Property Deviance}

The association between the big-five personality and property deviance was investigated using the Pearson product moment correlation coefficient. Table 1 indicates that personality dimensions were all significantly associated with property deviance. There was a significant negative association between surgency $(\mathrm{r}=-.128)$, agreeableness $(r=-.279)$, adjustment $(r=-.287)$, conscientiousness $(r=-.315)$ and openness to experience $(r$ $=-.217$ ) with property deviance, with a high level of conscientiousness controlling the occurrence of property deviance.

Studies also show an inverse relationship between personality and property deviance. In this case, if the organisation places emphasis on all dimensions of personality during the selection process and through to employment, it may reduce deviance tendencies. By referring to the findings, the strongest association was between conscientiousness followed by adjustment and agreeableness, which were instrumental in reducing property deviance. Openness to experience and surgency also play a role in reducing property deviance, though at a low level.

Conscientiousness indicates a highly responsible individual, willing to accept responsibilities and those who are committed to the job. Thus, they are highly disciplined individuals, who follow instructions and make the organisation and their bosses the main reference in the execution of their duties. This prevented them from engaging in negative behaviours. Adjustment is also identified as playing a role in the prevention property deviance. This personality trait assists individuals to control their emotions and work under pressure. As such, individuals are better equipped to meet challenge in the workplace, creating a balance of emotions and preventing them from engaging in negative conduct.

Agreeableness is described as individuals who can perform tasks within a group and those who emphasise the importance of the organisation and the group compared to adopting individualistic view points. Working in a highly-disciplined environment with a focus on integrity and ethical conduct is said to prevent deviance. Finally, openness to experience and surgency were also identified as traits that can prevent property deviance. These personality traits described an individual as imaginative and outgoing. Although they were least emphasised in public sectors, they nevertheless managed to control property deviance.

\section{Conclusion}

The findings indicate that property deviance continues to be highly reported. The respondents admitted the existence of property deviance including instances of forging an expenses account, stealing, corruption and bribery in public organisations. This in line with what is reported by the media and other agencies on this deviance. Property deviance involves fraud and dishonesty in the financial statements provided. Individuals are also involved in bribery by receiving remuneration for accelerating the processes involved, or allowing improper conduct by certain parties. This indicates that individuals show cooperative behaviour allowing misconduct to occur (Biron, 2010).

This misconduct requires the organisation to identify the contributing factors, and in this study, personality is identified as a factor influencing deviance property. This study highlighted the relationship between personality traits and property deviance, thus adding value to the ability of public organisation to identify the personalities concerned with deviant behaviour, and which personality dimensions contribute to property deviance. Taking into account the findings of this study, public organisations may recognise the contribution of conscientious, adjustment and agreeableness to reduce deviance (Farhadi et al., 2012).

Property deviance has the ability to negatively affect the reputation of public organisations, and lead to the development of negative values and norms within such organisations, making the ablity to control this behaviour necessary. The initiative to develop a desirable personality profile can begin with the labour recruitment process through to the recognition of employees, for example, through promotions. Highlighting personality tr that drive personal and organisational success, specifically in training and development activities, can cultivate a sense of belonging and personal accomplishment as employees can observe the implications of 
such traits if successfully developed. Further, the findings increase awareness among civil servants on the importance of personality that can help improve their performance, and it has relevance in regulating the existence of deviant behaviour (Hudson et al., 2012).

This study has successfully investigated the direct effect of personality and property deviance. Although workplace personality is recognised as surface diversity, there are other deep diversities representing psychological capital, including esteem and efficacy level, that may mediate or moderate the relationship. The inclusion of this psychological capital may validate the personality profile of employees, in the same way that environmental factors, such as leadership and organisational policy, may determine the collective personality exhibited at the workplace that may or may not represent the actual personality of public employees. The use of personality analysis during the interview stage may also reduce the common method variance, and may provide useful input for determining factors associated with property deviance.

\section{References}

Agboola, A. A., \& Salawu, R. O. (2011). Managing Deviant Behavior and Resistance to Change. Journal of Business and Management, 6(1), 235-243.

Andrews, R., \& Boyne, G. A. (2010). Capacity , Leadership , and Organizational Performance : Testing the Black Box Model of Public Manag ... Public Administration Review, 70(3), 443-454.

Betz, N. E., \& Borgen, F. H. (2010). Relationships of the Big Five Personality Domains and Facets to Dimensions of the Healthy Personality. Journal of Career Assessment, 18(2), 147-160. http://doi.org/10.1177/1069072709354200

Biron, M. (2010). Negative Reciprocity and Association between Perceived Organizational Ethical Values and Organizational Deviance. Human Relations, 63(6), 875-897. http://doi.org/10.1177/0018726709347159

Farhadi, H., Fatimah, O., Nasir, R., \& Wan Shahrazad, W. S. (2012). Agreeableness and Conscientiousness as Antecedents of Deviant Behavior in Workplace. Asian Social Science, 8(9), 2-7. http://doi.org/10.5539/ass.v8n9p2

Ghosh, R., Dierkes, S., \& Falletta, S. (2011). Incivility Spiral in Mentoring Relationships: Reconceptualizing Negative Mentoring as Deviant Workplace Behavior. Advances in Developing Human Resources, 13(1), 22-39. http://doi.org/10.1177/1523422311410639

Giauque, D., Anderfuhren-Biget, S., \& Varone, F. (2012). Stress Perception in Public Organisations: Expanding the Job Demands-Job Resources Model by Inlcuding Public Sevice Motivation. Review of Public Personnel Administration, $X X(\mathrm{X}), 1-26$. http://doi.org/10.1177/0734371X12443264

Hudson, N. W., Roberts, B. W., \& Lodi-Smith, J. (2012). Personality trait development and social investment in work. Journal of Research in Personality, 46, 334-344. http://doi.org/10.1016/j.jrp.2012.03.002

Kantur, D. (2010). Emotional Motives and Attitudinal Reflections of Workplace Deviant Behavior. The Business Review Cambridge, 14(2), 70-78.

Lodi-Smith, J., \& Roberts, B. W. (2007). Social investment and personality: a meta-analysis of the relationship of personality traits to investment in work, family, religion, and volunteerism. Personality and Social Psychology Review: An Official Journal of the Society for Personality and Social Psychology, Inc, 11(1), 68-86. http://doi.org/10.1177/1088868306294590

Lussier, R. N. (2008). Human Relations in Organizations: Applications and Skill Building (7th ed.). New York: McGrawHill.

Mehmood, I., \& Arif, M. I. (2011). Leadership and HRM : Evaluating New Leadership Styles for effective Human Resource Management. International Journal of Business and Social Science, 2(15), 236-244.

Robinson, S. L., \& Bennet, R. J. (1995). A typology of deviant workplace behaviors : A multdimensiona. Academy of Management Journal, 38(2), 555-572.

Vakola, M., Tsaousis, I., \& Nikolaou, I. (2004). The role of emotional intelligence and personality variables on attitudes toward organisational change. Journal of Managerial Psychology, 19(2), 88-119. 